\title{
Kalça eklemi anatomisi ve biyomekaniği
}

\author{
Anatomy and biomechanics of the hip joint
}

\author{
Ali Turgut
}

Tepecik Eğitim ve Araştırma Hastanesi, İzmir

\begin{abstract}
Kalça eklemi klasik bir top ve yuva tipi eklemdir. Yuvayı oluşturan asetabulum ilium, iskium ve pubis kemiklerinin birleşmesi ile oluşur. Asetabulum ortalama $20-40^{\circ}$ anteversiyona ve $40-50^{\circ}$ inklinasyona sahiptir. Asetabulum, labrum ile çevrelenmiştir. Labrum, eklem yüzü ve hacmini arttırır. Femur başı, bir kürenin 2/3'ü kadar yuvarlaklıkta ve \%60-70'i hyalin kıkırdakla kaplı olan bir yapıdır. Femur başı ve cismi arasında boyun bulunur. Femur boynu anteversiyon açısı erişkinlerde $15-20^{\circ}$ iken femur boynu ve cismi arasında, koronal planda $125 \pm 5^{\circ}$ kadar bir açılanma mevcuttur. Kalça eklemi, omuz ekleminden sonra hareket açıklığı en geniş olan ikinci eklemdir. Bu eklemin hareketlerinde 22 kas kullanılır. Eklem stabilitesi, esas olarak, iliofemoral, pubofemoral ve iskiofemoral bağlar vasıtasıyla sağlanır. Femur başının kanlanmasında, mediyal sirkumfleks femoral arter önemli rol oynar. Yürüme esnasında, kalça ekleminde yaklaşık $35^{\circ}$ fleksiyon, $20^{\circ}$ kadar da ekstansiyon hareketi gerçekleşir. Kalça eklemi üzerine binen yükler, esas olarak, vücut ağırlığı ve abduktor kas gücüdür.
\end{abstract}

Anahtar sözcükler: kalça eklemi; anatomi; biyomekanik
The hip joint is a classical ball and socket type joint. Acetabulum is formed by the coalision of iliac, pubic and ischial bones. Acetabulum has an average of $20-40^{\circ}$ anteversion and $40-50^{\circ}$ inclination. Acetabulum is surrounded by the labrum. Labrum increases the articular surface and joint volume. The femoral head has $2 / 3$ roundness of a sphere which is covered with hyaline cartilage. Femoral neck is located between the femoral head and body. Femoral neck anteversion angle is approximately $15-20^{\circ}$ in adults and there is a $125 \pm 5^{\circ}$ angulation between the femoral neck and shaft in the coronal plane. The hip is the second joint which has the widest range of motion after the shoulder joint. Twenty two muscles enable the movements of the hip joint. Joint stability is mainly provided by iliofemoral, pubofemoral and ischiofemoral ligaments. Medial circumflex femoral artery plays an important role on the blood supply to the femoral head. About $35^{\circ}$ of flexion and $20^{\circ}$ of extension of the hip joint is necessary during walking. The main loads imposed on the hip joint are abductor muscle strength and body weight.

Key words: hip joint; anatomy; biomechanics
K alça eklemi klasik bir top ve yuva tipi eklemdir. Sinoviyal eklemlerin sahip olduğu dört özelliği de barındırır; eklem kavitesi mevcuttur, eklem yüzeyleri kıkırdak ile kaplıdır, sinoviyal sıvı üreten membrana sahiptir ve bağlarla desteklenmiş bir kapsülle korunur. ${ }^{[1]}$

\section{KEMIKSEL ANATOMi}

Yuvayı oluşturan asetabulum, üç ayrı kemiğin birleşmesi ile oluşur. Bunlar; ilium (\%40), iskium (\%40) ve pubistir (\%20).[2] İskeleti immatür olanlarda bu üç ayrı bileşen, $Y$ kıkırdağı ile birbirlerinden ayrılır veya, bir başka deyişle, $Y$ kıkırdağı bu üç kemiğin bileşkesinde rol oynar. ${ }^{[3]}$ Bu üç kemiğin birleşmesi 14-16 yaşlarında başlar ve 23 yaşına kadar devam eder. ${ }^{[3]}$ Asetabulumun içine bakıldığında, at nalı şeklinde bir eklem kıkırdağı ve bu kıkırdağın ortasında sinoviyal doku ile kaplanmış olan fibroadipöz doku ile dolu asetabular çukur (cotyloid cavity) bulunmaktadır. Bu çukurun alt kenarında transvers asetabular bağ vardır. Asetabular hiyalin kıkırdak, yük binme yerinde (superior) en kalın iken (1,75-2,5 $\mathrm{mm})$, posteromediyal bölgede en incedir $(0,75-1,25$ $\mathrm{mm}) .^{[4]}$ Normalde, asetabular öne dönüklük 20-40 ve asetabular inklinasyon $40-50^{\circ}$ arasındadır. ${ }^{[5,6]}$

Kemik asetabulum, fibrokıkırdak yapıda olan labrum ile çepeçevre sarılmıştır. Labrumun, kalçanın

- İletişim adresi: Ali Turgut, Tepecik Eğitim ve Araştırma Hastanesi Ortopedi ve Travmatoloji Kliniği, İzmir Tel: 0537 - 0274425 e-posta: draliturgutort@yahoo.com.tr

- Geliș tarihi: 23 Ocak 2015 Kabul tarihi: 23 Ocak 2015 
eklemleşen yüzüne \%22'lik bir katkıda bulunduğu ve asetabulum hacmini \%33 oranında arttırdığı saptanmıştır. ${ }^{[7]}$ Labrum en geniş olarak, postero-inferior asetabular kenarda ölçülmüştür (ortalama $6,4 \pm 1,7 \mathrm{~mm}$ ); anterosuperior kadranda ise en dardır $(5,5 \pm 1,5 \mathrm{~mm})$. [8] Yapılan çalışmalar, en sık kalça artroskopisi yapılma nedeninin bu yapıda oluşan yırtıklar olduğunu bildirmektedir.[9] Labrum; eklem stabilitesine katkıda bulunur, sinoviyal sıvının dışa kaçmasını engelleyerek negatif eklem içi basıncı korur, normal asetabulum gelişimine destek olur ve eklem çevresi yük dağılımı sağlar. ${ }^{[10,11]}$ Labrumun kanlanması; obturator ve superiorinferior gluteal arterlerin dallarınca sağlanır. ${ }^{[12]}$ Labral yırtıklar, genellikle labrum-eklem kıkırdağı bileşkesinde oluşmaktadır (watershed area).

Femur başı, çapı 45-56 mm arasında değişebilen bir kürenin yaklaşık 2/3'ü kadar yuvarlıktadır. ${ }^{[13]}$ Femur başının \%60-70’i kıkırdak ile kaplıdır. Yük taşıyan superior bölgede hiyalin kıkırdak kalınlığı yaklaşık 2,5 mm'dir. Baş santralinde kıkırdak ile kaplı olmayan ve capitis femoris bağının yapıştığı bölgeye "fovea capitis" adı verilir. Capitis femoris bağının eklem stabilitesine çok az katkısı vardır. Femur başı ve femur cismi arasında, uzunluğu kişiden kişiye değiş̧ebilmekle birlikte, yaklaşık beş santimetre uzunlukta femur boynu mevcuttur. Femur boynu ve femur cismi arasında, koronal planda $125 \pm 5^{\circ}$ 'lik bir açılanma mevcuttur; aksiyel planda doğumda $30-40^{\circ}$ olan öne doğru açılanma, erişkinlerde yaklaşık $15-20^{\circ}$ 'ye azalır (anteversiyon). Bazı bireylerde bu anteversiyon artmış, bazılarında da tersine dönmüş olabilir (retroversiyon).

Özellikle kalçalara yük vermeyi gerektiren aktivitelerde, femurun üst ucu ciddi gerilme ve kompresyon yüklerine karşı koyar. Bu bölgedeki trabeküler kemik paterni, yüklere karşı koyabilecek şekilde gelişmiştir. Ward, bu trabeküllerin dağılımlarını ayrıntısı ile ortaya koymuştur. ${ }^{[14]}$ Birincil kompresyon trabekülleri, mediyal subtrokanterik korteksten başlayıp femur başının yük binen bölgesine ilerlerken, birincil gerilme trabekülleri fovea capitis bölgesinden trokanter majörün alt kısmına doğru ilerler. İkincil kompresyon ve gerilme trabekülleri ile birlikte trokanter majör grubu trabekülleri, bu düzenlemenin geriye kalan kısımlarıdır. Posteromediyal femoral korteksten trokanter majörün posterioruna uzanan sert kemik kısma "kalkar femorale" denilmektedir. ${ }^{[15]}$

\section{EKLEM KAPSÜLÜ}

Kalça ekleminin stabilitesi güçlü bir kapsüler yapı ile desteklenir. Kapsül asetabulumun kemik kısmına labruma 6-8 mm mesafede yapışır. ${ }^{[8]}$ Kapsül, femoral tarafta önde intertrokanterik hatta yapışırken, arkada intertrokanterik hattın biraz daha üzerine femur başı tarafına yapışır. ${ }^{[16]}$ Pelvisi femura bağlayan ve kapsülü güçlendiren kapsül dışı üç adet bağ mevcuttur: iskio-femoral, pubo-femoral, ilio-femoral. Bu bağlar, kalça eklemi ekstansiyonda iken genellikle fleksiyon, abduksiyon ve dış rotasyon hareketlerinde gevşer. ${ }^{[17]}$ En güçlüleri, diğer adı Bigelow bağı olan ilio-femoral bağdır; bu bağ, anterior-inferior iliak çıkıntıdan iki ayrı bant şeklinde başlayıp, anterior intertrokanterik çizgiye ters $Y$ şeklinde yapışır. illio-femoral bağ, esas olarak hiperekstansiyona karşı koyarken, pubofemoral bağ hiperabduksiyona karşı direnç oluşturur. ìskio-femoral bağ, temel olarak ekstansiyondaki kalçayı dengede tutmaya yardımcı olur; diğer iki bağın arasında bulunur ve her iki bağ ile arasında oluşan boşluklar zayıf noktalardır. Öne ve arkaya kalça çıkıkları genellikle bu zayıf aralıklardan olur. ${ }^{[2]}$ Kalça ekleminde bulunan iki adet daha bağ mevcuttur: zona orbicularis - angular bağ, ligamentum capitis femoris). Bu iki bağ da kalça ekleminin stabilitesine az miktarda katkı sağlayabilir.

\section{ASETABULUM VE FEMUR BAŞININ KANLANMASI}

Asetabulum temel olarak üç kaynaktan beslenir. Bu kaynaklar; obturator, superior gluteal ve inferior gluteal arterlerdir. Asetabulumun superior ve posterior kısımlarını superior gluteal arter, inferior ve posterior kısımlarını inferior gluteal arter beslerken, mediyal kısım obturator arterin asetabular dalından beslenir.

Femur başı ve boynu, mediyal-lateral sirkumfleks femoral arterler tarafindan beslenir. Mediyal sirkumfleks femoral arterin bir dalı olan "lateral epifizeal arter" femur başının yük binen kısmını ve hemen hemen yarısını besler. ${ }^{[18]}$ Lateral sirkumfleks femoral arterden çıkan ve eklem kapsülünü femoral yapışma yerine yakın yerden delerek kapsül içerisine giren ve femur boynu boyunca, retinakuler dallar vererek ilerleyen "çıkan ascending - arterler" gerek kırıklarda gerekse eklem içi basıncın arttığı durumlarda (enfeksiyon, hematom) risk altındadır. ${ }^{[19]}$

\section{KALÇA EKLEMi iNNERVASYONU}

Kalça eklemi innervasyonunun büyük kısmını, quadratus femoris kasını innerve eden sinirin bir dalı olan, posterior artiküler sinir sağlar. Superior kısımda eklem kapsülü superior gluteal sinir, ön kapsül kısmı femoral sinir dalları tarafından innerve edilir. Anteroinferior ve anteromediyal kapsül, obturator sinirin ön dalından ayrılan mediyal artiküler sinir tarafindan innerve edilir. ${ }^{[16]}$ 


\section{KAS ANATOMISi}

Kalça anatomisi, birçok kasın fonksiyon gösterdiği, her yönde rotasyonel hareketlere izin verebilen bir yapıdır. Kalça eklemi üzerine etkisi olan 22 kasın görevi, sadece hareket değil aynı zamanda kalça stabilitesine katkı sağlamaktır. ${ }^{[20]}$

Kalça ve uyluk kasları, fasya lata adı verilen fibröz bir kılıf ile sarılıdır. Fasya lata, proksimalde inguinal bağa, iliak kanata, sakrum posterioruna, iskial çıkıntıya, pubis ve pübik tüberküle yapışmaktadır. ${ }^{[3]}$

Kalça ekleminin ana fleksör kası ileopsoas'tır. Bu kas, psoas major-minör ve iliacus'tan oluşur. Psoas major, torakal 12 - lomber 5 omurga cisimlerinden başlayıp küçük trokantere yapışır. İnguinal bağ seviyesinde psoas major ve iliacus kasları birleşerek “ileopsoas” kasını oluşturur. ${ }^{[2]}$ Ileopsoas kasına, kalça fleksiyonunda sartorius, rectus femoris, pectineus ve tensor fascia lata kasları yardımcı olur. Kalça ekleminin en güçlü ekstansör kası gluteus maximus'tur. Birincil abduktorlar gluteus medius ve minimus kaslarıdır. Kalça iç rotasyonunu birincil olarak yaptıran kas yoktur, ancak tensor fascia lata, gluteus medius'un ön yüzü ve gluteus minimus ikincil olarak kalçaya iç rotasyon yaptırır. Kalça dış rotasyonu pelviste başlayıp trokanter majörün arka yüzüne yapışan kısa kaslarca sağlanır. Bu kaslar; obturator internus, obturator externus, gemellus superior, gemellus inferior, piriformis ve quadratus femoris'tir. ${ }^{[16]}$ Kalça eklemi ile ilgili kaslar Tablo 1'de özetlenmiştir.

Tablo 1. Kalça çevresi kasların özellikleri

\begin{tabular}{|c|c|c|c|c|}
\hline Fonksiyon & Kas & Başlangıç & Yapışma & İnnervasyon \\
\hline \multirow[t]{4}{*}{ Fleksiyon } & iliopsoas & $\begin{array}{l}\text { T12-L5 transvers çıkıntı, } \\
\text { iliak kanat ve sakrum superioru }\end{array}$ & Küçük trokanter & Femoral sinir \\
\hline & rectus femoris & SiAi, antero-superior asetabulum & Patella üst ucu & Femoral sinir \\
\hline & tensor fascia lata & SIAS ve iliak kanat & İliotibial bant & Superior gluteal sinir \\
\hline & sartorius & SIAS & Anteromediyal tibial plato & Femoral sinir \\
\hline \multirow[t]{4}{*}{ Ekstansiyon } & gluteus maximus & $\begin{array}{l}\text { Illiak kanat dış kısmı, arka sakrum ve } \\
\text { koksigis }\end{array}$ & $\begin{array}{l}\text { Posterior iliotibial band ve } \\
\text { gluteal çıkıntı }\end{array}$ & Inferior gluteal sinir \\
\hline & biceps femoris & İskial çıkıntı & $\begin{array}{l}\text { Fibula başı ve } \\
\text { posterolateral tibial plato }\end{array}$ & Siyatik sinirin tibial dalı \\
\hline & semimembranosus & İskial çıkıntı & Posteromediyal tibial plato & Siyatik sinirin tibial dalı \\
\hline & semitendinosus & İskial çıkıntı & Anteromediyal tibial plato & Siyatik sinirin tibial dalı \\
\hline \multirow[t]{3}{*}{ Abduksiyon } & gluteus medius & Ön gluteal çizgi & Büyük trokanterin lateral yüzü & Superior gluteal sinir \\
\hline & gluteus minimus & İlium dış korteksi & Büyük trokanterin ön yüzü & Superior gluteal sinir \\
\hline & tensor fascia lata & ASiS ve iliak kanat & İliotibial bant & Superior gluteal sinir \\
\hline \multirow[t]{3}{*}{ Adduksiyon } & adductor magnus & İnferior pübik ramus, iskial çıkıntı & Gluteal çıkıntı ve adduktor tüberkül & Obturator sinir ve siyatik sinir \\
\hline & adductor longus & Pubis cismi & Linea asperanın orta $1 / 3$ 'ü & Obturator sinir \\
\hline & adductor brevis & İnferior pübik ramus ve pubis cismi & $\begin{array}{l}\text { Proksimal linea aspera ve } \\
\text { pektineal çizgi }\end{array}$ & Obturator sinir \\
\hline \multirow[t]{3}{*}{ İç rotasyon } & gluteus medius & Ön gluteal çizgi & Büyük trokanterin lateral yüzü & Superior gluteal sinir \\
\hline & gluteus minimus & Illium dış korteksi & Büyük trokanterin ön yüzü & Superior gluteal sinir \\
\hline & tensor fascia lata & ASiS ve iliak kanat & Illiotibial bant & Superior gluteal sinir \\
\hline \multirow[t]{6}{*}{ Dış rotasyon } & obturator internus & Obturator membranın iç yüzü & Büyük trokanterin mediyali & Obturator internus siniri \\
\hline & obturator externus & $\begin{array}{l}\text { Obturator membranın dış kısmı, } \\
\text { pübik ramus, iskium }\end{array}$ & Trokanterik çukur & Obturator sinir \\
\hline & superior gemellus & İskial boynuz & Büyük trokanterin arka yüzü & Obturator internus siniri \\
\hline & inferior gemellus & İskial çıkıntı & Büyük trokanterin arka yüzü & Kuadratus femoris siniri \\
\hline & piriformis & Sakrumun ön yüzü ve sakrotüberoz bağ & Büyük trokanterin posterosuperioru & S1 ve S2'nin ön dalları \\
\hline & quadratus femoris & İskial çıkıntının lateral kısmı & Kuadrat tüberkül & Kuadratus femoris siniri \\
\hline
\end{tabular}

T, torakal; L, lomber; SIAI, spina iliaka anterior inferior; SIAS, spina iliaka anterior superior 


\section{KALÇA EKLEMI BIYOMEKANIĞi}

Kalça mekaniğinin anlaşılması; kalça fonksiyonlarının öğrenilmesi, kalça sorunları ile ilgili tedavi yöntemlerinin geliştirilmesi, rekonstrüktif girişimlerin planlanması ve kalça protezlerinin geliştirilmelerinde oldukça önemlidir. Kalça eklemi, günün her saatinde az da olsa bir miktar yüke maruz kalmaktadır. Bu yük; sandalyeden kalkma, merdivenden inme, merdivenden çıkma, koşma, oturma, çömelme gibi hareketlerde değişir.

Normalde; sagittal planda $120-130^{\circ}$ fleksiyon, $10-$ $15^{\circ}$ ekstansiyon hareketi yapılabilir. ${ }^{[21]}$ Kalça fleksiyon hareketi; kapsülo-ligamentöz yapılar, kaslar ve kemikler tarafından kısıtlanabilir. Kalça ve diz eklemini geçen hamstring kaslarından ötürü, diz eklemi ekstansiyonda iken kalça fleksiyonu azalır. ${ }^{[21]}$ illiofemoral bağ, ön kapsül ve kalça fleksör kasları ise ekstansiyonu azaltır. Kalça fleksiyonda iken, iç rotasyon hareketi $0-70^{\circ}$ arasında, dış rotasyonu da $0-90^{\circ}$ arasında değişir. ${ }^{[22]}$ Kalça ekstansiyonda iken çevre yumuşak dokular daha fazla gerilim altında olduklarından, kalça iç ve dış rotasyon hareketleri azalır. Asetabulum veya femur anteversiyon değişikliklerinde de, rotasyonel hareket genişlikleri artar veya azalır. Her iki taraf anteversiyonu azaldığında iç rotasyon hareketi azalır, arttığında ise buna paralel olarak iç rotasyon artar. Anteversiyon açıları arttığında dış rotasyon hareketi azalır; azaldığında ise dış rotasyon artar.

Kalça ekleminin toplam hareketine, pelvis hareketi de etki eder. Yapılan bir çalışmada; dizler fleksiyonda iken kalça fleksiyonunun \%26'sının lumbopelvik rotasyon ile sağlandığı, dizler ekstansiyonda iken ise bu oranın \%39 olduğu saptanmıştır. ${ }^{[23]}$ Özellikle son yıllarda dikkat çeken femoro-asetabular sıkışma sendromunda olduğu gibi, proksimal femur ve asetabular kenar değişiklikleri de kalça hareket kısıtılıkları ve fonksiyonel bozukluklarının önemli bir kısmını oluşturur. ${ }^{[24]}$ Böyle durumlarda, pelvik rotasyon hareketi daha erken devreye girer.

Günlük aktivitelerde gerekli olan kalça hareket genişlikleri Tablo 2'de gösterilmiştir. ${ }^{[25]}$

Tablodan da anlaşılacağı gibi, $120^{\circ}$ 'lik fleksiyon ve $20^{\circ}$ 'lik dış rotasyon-abduksiyon hareketi birçok gündelik hareket için gereklidir. Yaşlandıkça kalça fleksiyonekstansiyon hareket açıklığı ve adım aralığı azalır. ${ }^{[26]}$

Yürüme esnasında kalça hareketleri ile ilgili ayrıntılı bilgi Tablo 3'te gösterilmiştir. ${ }^{[27]}$

\section{KALÇA EKLEMI ÜZERINE ETKIYEN YÜKLER}

Kalça üzerine etkiyen kuvvetlerin ölçülmesi, ancak endoprostetik girişimler sonrası mümkün olabilmiştir. Tek bacak üzeri duruşta, serbest vücut diyagramında kalça eklemi üzerine etkiyen yükler, ortopedi literatüründe kendisine sıkça yer bulmuştur. ${ }^{[28]} \mathrm{Bu}$ ölçümler, pelvisin dengede tutulması için gerekli olan kuwvetleri statik durumda, sadece frontal planda göstermektedir. Buna göre, kalça eklemine; yerçekimi kuvveti (vücut ağırlığı - karşı alt ekstremite ağırlığı - vücut ağıllığının yaklaşık 5/6'sı kadardır), abduktor kol kuweti (pelvisi dengede tutmaya yarayan güç) ve eklem reaksiyon gücü (femur başına etkiyen toplam kuvvet) etkimektedir (Şekil 1). Vücut ağırlığı ve kaldıraç kol uzunlukları kolaylıkla ölçülebilir, basit bir fizik hesabı ile abduktor kol kuweti de hesaplanabilir (Şekil 1'e göre, $c \times a=b \times d$ ). Tüm bu ölçümler sonucunda, güç vektörleri göz önünde bulundurularak, tek ayak üzerinde durulduğunda pelvis yere paralel iken femur başına binen yük, vücut ağırlığının 2,7-3,4 katı kadar ve horizontal çizgiden $69^{\circ}$ uzaktadır. ${ }^{[22]}$ Şekil 1'e göre, bu yük vektörleri aşağıdaki gibidir.

Tablo 2. Gündelik yaşamda sık yapılan hareketlerde ölçülen maksimum kalça hareketlerin planlara göre dağııımı

\begin{tabular}{|c|c|c|}
\hline Aktivite & $\begin{array}{l}\text { Hareket } \\
\text { Düzlemi }\end{array}$ & $\begin{array}{c}\text { Derece } \\
\left({ }^{\circ}\right)\end{array}$ \\
\hline \multirow{3}{*}{$\begin{array}{l}\text { Ayak yerdeyken } \\
\text { ayakkabı bağlama }\end{array}$} & Sagittal & 124 \\
\hline & Frontal & 19 \\
\hline & Transvers & 15 \\
\hline \multirow{3}{*}{$\begin{array}{l}\text { Ayak karşı uyluktayken } \\
\text { ayakkabı bağlama }\end{array}$} & Sagittal & 110 \\
\hline & Frontal & 23 \\
\hline & Transvers & 33 \\
\hline \multirow[t]{3}{*}{ Sandalyeye oturup kalkma } & Sagittal & 104 \\
\hline & Frontal & 20 \\
\hline & Transvers & 17 \\
\hline \multirow{3}{*}{$\begin{array}{l}\text { Yerden bir şey almak için } \\
\text { alçalma }\end{array}$} & Sagittal & 117 \\
\hline & Frontal & 21 \\
\hline & Transvers & 18 \\
\hline \multirow[t]{3}{*}{ Çömelme } & Sagittal & 122 \\
\hline & Frontal & 28 \\
\hline & Transvers & 26 \\
\hline \multirow[t]{3}{*}{ Merdiven çıkma } & Sagittal & 67 \\
\hline & Frontal & 16 \\
\hline & Transvers & 18 \\
\hline Merdiven inme & Sagittal & 36 \\
\hline
\end{tabular}


Tablo 3. Yürüme fazlarına göre kalça hareketlerinin özellikleri

\begin{tabular}{lll}
\hline Yürüme fazı & Kalça hareketi & Aktif kaslar \\
\hline Duruş & $30^{\circ}$ fleksiyon & \\
Topuk teması & $0^{\circ}$ fleksiyon-ekstansiyon & Hamstringler, gluteus maksimus \\
Duruş ortası & $10^{\circ}$ ekstansiyon & $\begin{array}{l}\text { Gluteus medius-minimus-tensor fasya lata } \\
\text { illiakus }\end{array}$ \\
Duruş sonu & $0^{\circ}$ fleksiyon-ekstansiyon & iliakus, adduktor longus \\
Salınım öncesi & & \\
Salınım & $20^{\circ}$ fleksiyon, $5^{\circ}$ abduksiyon & iliopsoas, rektus femoris, grasilis, sartorius \\
Salınım başı & $20-30^{\circ}$ fleksiyon & iliopsoas, grasilis, sartorius \\
Salınım ortası & $30^{\circ}$ fleksiyon & Hamstringler ve gluteus maksimus \\
Salınım sonu &
\end{tabular}

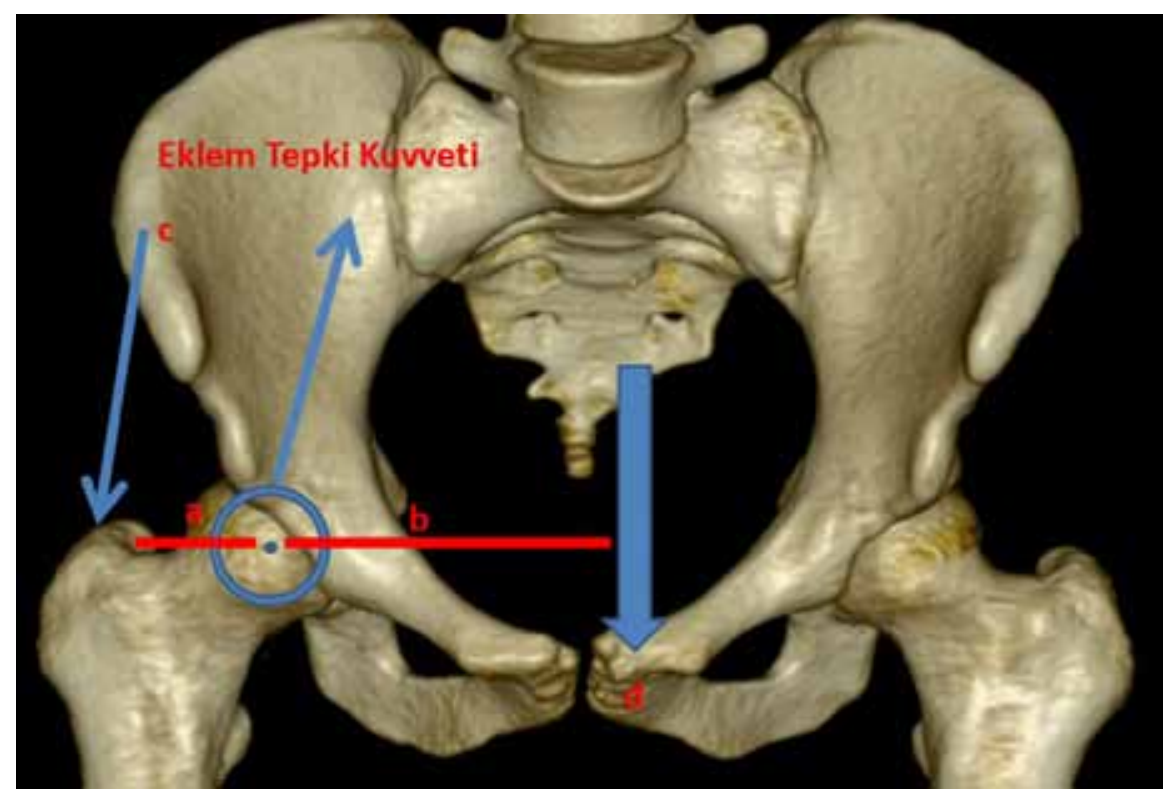

Şekil 1. Sağ kalça eklemi üzerine etkiyen kuvvetler (a, abduktor kaldıraç kolu; b, vücut ağırlığı kaldıraç kolu; c, abduktor kas gücü; d, vücut ağırlı̆̆ı).

Trendelenburg bulgusu, vücut ağırlık kuvvetine abduktor kasların karşı koyamaması sonucu oluşur ve pelvis tek ayak üzerinde dururken yere paralelliğini koruyamaz; yani, bir başka deyişle, kalça eklem reaksiyon gücü, bu durumda abduktor güç azaldığından dolayı azalacaktır.

Pauwels, her iki ayak yere basarken iki kalçaya da eşit yük bindiği sonucuna varmıştır. Normalde vücut ağırlığı, sakral ikinci vertebra önünden geçer ve her iki ayak yere basarken, pelvisin ortasından geçer; ancak, tek ayak yere basarken diğer ayak yerden kalktığı için, ağırlık merkezi ortanın basmayan tarafına kayar. ${ }^{[28]}$ Yürüme esnasında, topuk temasında femur başının antro-supero-mediyali, salınım fazı başlangıcında ise postero-supero-laterali yük altında kalmaktadır.[29] Yürürken bir kalçanın karşı tarafında koltuk değneği kullanılması, vücut ağırlığını ve dolayısı ile pelvisi dengede tutması gereken abduktor kas gücünü, nihai olarak da eklem reaksiyon gücünü azaltır. ${ }^{\left[{ }^{30]}\right.}$ Yapılan çalışmalarda, tek tarafta koltuk değneği kullanımının, gerekli abduktor kas gücünü \%20-42 arasında, eklem reaksiyon kuvvetini de vücut ağırlığının 3,4 katından 2,2 katına kadar azalttığı bulunmuştur. ${ }^{[31]}$ Bir kalçaya binen yükü azaltmak için, vücut ağırlığı ve abduktor kas gücü azaltılmalıdır. Bunun da yolları; kilo vermek, koltuk değneği gibi yardımcı cihazlar kullanmak ve abduktor kaldıraç kolunu uzatarak vücut ağırlığı kaldıraç kolunu kısaltmaktır. 
Kalça üzerine binen yüklerin dinamik olarak da ölçülmeleri çeşitli çalışmalarda başarılmıştır. ${ }^{[32-37]} \mathrm{Bu}$ çalışmaların sonuçları şu şekilde özetlenebilir;

- Yavaş yürümenin topuk temasından hemen sonra kalça eklemine vücut ağırlığının üç katı kadar, parmaklar kalkarken de dört katı kadar yük binmektedir.

- Hızlı yürümede bu yükler, vücut ağırlığından daha az olmak üzere, artmaktadır.

- Koşmada, topuk temasından hemen sonra kalçaya vücut ağırlı̆̆ının 7-8 katı kadar yük binmekte iken, bu oran salınım fazı başlangıcında biraz daha yüksektir.

- Kayak ile kayma esnasında, kalça eklemlerine vücut ağırlığının 4-12,4 katı kadar yük biner.

- İki ayak üzerinde dururken, kalça eklemlerine vücut ağırlı̆ıııın 0,8-1 katı kadar yük biner.

Kalçanın biyomekaniğinin anlaşılması bir deformitenin düzeltilmesinde oldukça önemlidir. Örneğin koksa valga varlığında abduktor kaldıraç kolunun kısaldığı, asetabular kapsanmanın azalabileceği dolayısı ile kalça ekleminin reaksiyon kuvvetinin artacağı ve olası asetabular displazi varlığında da, yük taşıyan eklem kıkırdağında stresin artacağı bilinmelidir. Böyle bir durumla karşılaşıldığında yapılması gereken, proksimal femoral varus osteotomisi ile abduktor kaldıraç kolunu uzatmak ve gerekli ise pelvik osteotomi ile femur başı örtünmesini arttırmaktır.

\section{KAYNAKLAR}

1. Thomas Byrd JW. Gross anatomy. In: Thomas Byrd JW, editor. Operative Hip Arthroscopy, 2nd ed. New York: Springer Science Business Media, Inc; 2005. p.100-9.

2. Schuenke M, Schulte E, Schumacher U. THIEME Atlas of Anatomy. In: Ross L, Lamperti E, editors. General Anatomy of the Musculoskeletal System. New York: Thieme New York; 2006.

3. Moore K, editor. Clinically Oriented Anatomy, 3rd ed. Baltimore: Williams and Wilkins 1992.

4. Macirowski T, Tepic S, Mann RW. Cartilage stresses in the human hip joint. J Biomech Eng 1994;116(1):10-8.

5. Neumann DA. Kinesiology of the Musculoskeletal System: Foundations for Physical Rehabilitation. St Louis, Mo: Mosby; 2002. p.387-433.

6. Kapandji IA. The Physiology of the Joints: Annotated Diagrams of the Mechanics of the Human Joints, 2nd ed. New York, NY: Churchill Livingstone; 1983.

7. Simon SR, Alaranta $\mathrm{H}$, An $\mathrm{KN}$, et al. Kinesiology. In: Buckwalter JA, Einhorn TA, Simon SR, American Academy of Orthopaedic Surgeons, editors. Orthopaedic basic science: Biology and biomechanics of the musculoskeletal system, 2nd ed. Rosemont, IL: American Academy of Orthopaedic Surgeons; 2000. p.782-8.

8. Seldes RM, Tan V, Hunt J, Katz M, Winiarsky R, Fitzgerald RH Jr. Anatomy, histologic features, and vascularity of the adult acetabular labrum. Clin Orthop Relat Res 2001;(382):232-40.
9. Thomas Byrd JW. Indications and contraindications. In: Thomas Byrd JW, editor. Operative Hip Arthroscopy, 2nd ed. New York: Springer Science Business Media, Inc; 2005. p.6-35.

10. Kim $\mathrm{YH}$. Acetabular dysplasia and osteoarthritis developed by an eversion of the acetabular labrum. Clin Orthop Relat Res 1987;(215):289-95.

11. Ferguson SJ, Bryant JT, Ganz R, Ito K. An in vitro investigation of the acetabular labral seal in hip joint mechanics. J Biomech 2003;36(2):171-8.

12. McCarthy JC, Noble PC, Schuck MR, Wright J, Lee J. The Otto E. Aufranc Award: the role of labral lesions to development of early degenerative hip disease. Clin Orthop Relat Res 2001;(393):25-37.

13. Williams PL, Warwick R, Dyson M, Bannister LH. Gray's Anatomy, 37th ed. Edinburgh, UK: Churchill Livingstone; 1989. p.552.

14. Ward FO. Human Anatomy. London: Renshaw; 1838.

15. DeLee JC. Fractures and dislocations of the hip. In: Rockwood CA, Green DP, Bucholz RW, et al., editors. Fractures in Adults. Philadelphia, PA: Lippincott-Raven; 1996. p.1666-7.

16. Robbins CE. Anatomy and biomechanics, In: Fagerson TL, editor. The Hip Handbook. Boston, MA: ButterworthHeinemann; 1998. p.1-37.

17. Sim FH, Rock MG, Scott SG. Pelvis and hip injuries in athletes: Anatomy and function. In: Nicholas JA, Hershman EB, editors. The Lower Extremity \& Spine in Sports Med, 2nd ed. Saint Louis, MO: Mosby; 1995. p.1025-65.

18. Trueta J, Harrison $\mathrm{MH}$. The normal vascular anatomy of the femoral head in adult man. J Bone Joint Surg $\mathrm{Br}$ 1953;35-B(3):442-61.

19. Soto-Hall R, Johnson LH, Johnson R. Alterations in the intraarticular pressure in transcervical fractures of the hip. J Bone Joint Surg Am 1963;45:662.

20. Byrne DP, Mulhall KJ, Baker JF. Anatomy \& biomechanics of the hip. The Open Sports Medicine Journal 2010;4(1):51-7.

21. Hamill J, Knutzen KM. Biomechanical Basis of Human Movement, 3rd ed. Baltimore: Lippincott Williams \& Wilkins; 2009. p.187-254.

22. Nordin M, Frankel VH. Basic Biomechanics of the Musculoskeletal System 3rd ed. Baltimore: Lippincott Williams \& Wilkins; 2001. p.203-21.

23. Dewberry MJ, Bohannon RW, Tiberio D, Murray R, Zannotti CM. Pelvic and femoral contributions to bilateral hip flexion by subjects suspended from a bar. Clin Biomech (Bristol, Avon) 2003;18(6):494-9.

24. Ganz R, Parvizi J, Beck M, Leunig M, Nötzli H, Siebenrock KA. Femoroacetabular impingement: a cause for osteoarthritis of the hip. Clin Orthop Relat Res 2003;(417):112-20.

25. Johnston RC, Smidt GL. Hip motion measurements for selected activities of daily living. Clin Orthop Relat Res 1970;72:205-15.

26. Murry R, Bohannon R, Tiberio D, Dewberry M, Zannotti C. Pelvifemoral rhythm during unilateral hip flexion in standing. Clin Biomech (Bristol, Avon) 2002;17(2):147-51.

27. Hughes PE, Hsu JC, Matava MJ. Hip anatomy and biomechanics in the athlete. Sports Med Arthrosc Rev 2002;10(2):103-14.

28. Pauwels F. Biomechanics of the Locomotor Apparatus: Contributions on the Functional Anatomy of the Locomotor Apparatus. Berlin: Springer-Verlag; 1980.

29. Frankel H. Biomechanics of the Hip. In: Tronzo RG, editor. Surgery of the Hip Joint. Philadelphia: Lea \& Febiger; 1973. p.105-25. 
30. Brinckmann P, Frobin W, Leivseth G. Musculoskeletal Biomechanics. Stuttgart: Thieme; 2002. p.69-84.

31. Neumann DA. Hip abductor muscle activity as subjects with hip prostheses walk with different methods of using a cane. Phys Ther 1998;78(5):490-501.

32. Bergmann G, Deuretzbacher G, Heller M, Graichen F, Rohlmann A, Strauss J, Duda GN. Hip contact forces and gait patterns from routine activites.J Biomech 2001;34(7):859-71.

33. Novacheck TF. The biomechanics of running. Gait Posture 1998;7(1):77-95.
34. Winter DA. Biomechanics and Motor Control of Human Movement, 4th ed. New York: Wiley; 2009.

35. Paul JP. Forces transmitted by joints in the human body. Proc Inst Mech Eng 1967;181:318-15.

36. Paul JP. Force actions transmitted by joints in the human body. Proc R Soc Lond Ser B 1976;192:163-72.

37. Morrison JB. Bioengineering analysis of force actions transmitted by the knee joint. Biomed Eng 1968;3(4):164-70. 